Primer semestre de 2019 - pp. 149-160 Segunda época

\title{
Literatura y memoria \\ histórica en la escuela. \\ Una experiencia \\ pedagógica e investigativa
}

$\begin{array}{ll}\text { Literature and } & \text { Literatura e } \\ \text { Historical Memory at } & \text { memória histórica } \\ \text { School: A Pedagogical } & \text { na escola. Uma } \\ \text { and Research } & \text { experiência } \\ \text { Experience } & \text { pedagógica e de } \\ & \text { pesquisa }\end{array}$

Nylza Offir García Vera* Orcid: https://orcid.org/0000-0002-0277-2587

Fernando González Santos**
García Vera, N. y González Santos, F. (2019). Literatura y memoria histórica en la escuela. Una experiencia pedagógica e investigativa. Folios, 49, 149-160. doi: 10.17227/Folios.49-9402

Alo recibido

$23 \cdot 06 \cdot 2017$

Artículo aprobado $20 \cdot 06 \cdot 2018$

* Magíster en Educación. Profesora Facultad de Educación, Universidad Pedagógica Nacional. Correo electrónico: nogarcia@pedagogica.edu.co

* Magíster en Filosofía. Profesor Facultad de Educación, Universidad Pedagógica Nacional.Correo electrónico: fgonzalezs@pedagogica.edu.co 


\section{Resumen}

El presente artículo de investigación señala cómo el vínculo entre literatura y memoria está anclado a las posibilidades pedagógicas de la lectura de novelas que escenifican el conflicto colombiano y permiten acercarse a los acontecimientos históricos, desde el campo de la sensibilidad y la percepción estética que proporcionan el arte y la imaginación literaria. Tomando como punto de partida la lectura de cinco novelas colombianas que, en conjunto, hacen un recorrido por los efectos de la violencia política en Colombia, desde los años 1950 hasta nuestros días, docentes y estudiantes del Instituto Pedagógico Nacional, en Bogotá, dan cuenta de cómo, gracias a la literatura, la memoria interpela nuestro lugar en el presente, configura nuevos lazos sociales y dispone nuestra subjetividad hacia relaciones éticas de solidaridad con las víctimas y los dramas humanos.

\section{Palabras clave}

literatura; memoria histórica; educación

Abstract

This research paper points out how the link between literature and memory is anchored to the pedagogical possibilities of reading novels that show the Colombian conflict and enable the approach to historical events from the field of sensitivity and the aesthetic perception provided by art and literary imagination. Using as a starting point the reading of five Colombian novels that, as a whole, give an account of the effects of political violence in Colombia, from the 1950s to present day, teachers and students from Instituto Pedagógico Nacional in Bogotá tell us how, thanks to literature, memory challenges our place in the present, establishes new social bonds and arranges our subjectivity towards ethical relations of solidarity with the victims and with human tragedies.

\section{Keywords}

literature; historical memory; education

\section{Resumo}

0 presente artigo de pesquisa assinala como o vínculo entre literatura e memória está fixado nas possibilidades pedagógicas da leitura de novelas que encenam o conflito colombiano e permitem aproximar-se aos conhecimentos históricos, desde o campo da sensibilidade e a percepção estética que proporcionam a arte e a imaginação literária. Tendo como ponto de partida a leitura de cinco romances colombianos que, em conjunto, fazem um percorrido pelos efeitos da violência política na Colômbia, desde os anos 1950 até hoje, docentes e estudantes do Instituto Pedagógico Nacional, em Bogotá, dão conta de como, graças à leitura, a memória interpela nosso lugar no presente, configura novos vínculos sociais e dispõe nossa subjetividade para relações éticas de solidariedade com as vítimas e os dramas humanos.

\section{Palavras-chave}

literatura; memória histórica; educação 


\section{Introducción}

El presente artículo se deriva del proyecto "La literatura como universo simbólico de la memoria en la escuela", ${ }^{1}$ cuyo núcleo ha consistido en la lectura de novelas relativas al conflicto político colombiano, con estudiantes y docentes del Instituto Pedagógico Nacional. La literatura es considerada aquí un tipo de lenguaje que contiene en sí mismo una percepción particular de los acontecimientos que han constituido la guerra colombiana y las secuelas en sus víctimas, diferente a discursos jurídicos, históricos o sociológicos y más allá de un juicio o un argumento analítico. La preocupación, en cambio, de las novelas que retoman la tragedia política nacional, se sitúa en las condiciones humanas de quienes han formado parte de una de las más dramáticas violencias del continente, causando la muerte de más de $220 \mathrm{mil}$ personas, de las cuales 180 mil (o sea el 81\%) eran civiles, más de 25 mil desapariciones forzadas y cerca de 6 millones de personas desplazadas de su territorio ( $c f r$. CNMH, 2013).

Frente a semejante panorama, la memoria tiene un lugar imprescindible en la reconstrucción de los lazos sociales de un país, que ha acumulado en las seis últimas décadas sentimientos de dolor, venganza y retaliación entre los ciudadanos. En esa perspectiva, la literatura, entre otras expresiones del arte, tiene la posibilidad de afectar la sensibilidad, de lograr nuevas formas de leer los efectos del conflicto e indagar en los lugares más profundos de las personas y las comunidades afectadas, en el sentido que un día lo dijera Julio Cortázar:

En todos los casos, positivos o negativos, de esa relación entre realidad y literatura, de lo que se trata en el fondo, es de llegar a la verdad por las vías de la imaginación, de la intuición, de esa capacidad de establecer relaciones mentales y sensibles que hacen surgir las evidencias y las revelaciones que pasarán a formar parte de una novela, o de un cuento, o de un poema. (Cortázar, 2013, p. 291).

1 Financiado por el Centro de Investigaciones de la Universidad Pedagógica Nacional entre 2015 y 2016.
De ahí que la literatura en la educación tenga hoy gran pertinencia, al permitirnos comprender desde el prisma de la imaginación narrativa los modos en que muchas generaciones de colombianos han sido afectadas por esta violencia sociopolítica que parece no tener fin. Ahora bien, ante la inquietud de si, desde la literatura, es posible que la cultura logre decantar su riqueza en medio de la fragmentación de las poblaciones, Carlos Fuentes afirma:

Sí [...], si nos damos cuenta de que una cultura es su imaginación, de que una historia es su memoria y de que una cultura incapaz de recrear sus propias imágenes, o una historia incapaz de imaginar su propia memoria, están destinadas a desaparecer. El pasado es nuestra agenda. (Fuentes, 2011, p. 70).

\section{Los vínculos entre literatura, educación y memoria}

El proyecto investigativo que antecede a las reflexiones que aquí se presentan se gestó desde la pregunta por cómo leer y reconstruir colectivamente la memoria histórica, a partir del cuerpo simbólico que ha constituido la literatura, y en particular, la novela, en cuanto forma expresiva que viene interpretando estéticamente los acontecimientos violentos derivados de las últimas décadas de guerra en Colombia. Dicha pregunta insinúa una tensión con la visión tradicional de la lectura literaria en la educación formal, puesto que gran parte de este lenguaje narrativo está al margen de los currículos, del canon aceptado o de los planes de lectura, lo cual muchas veces despoja a las prácticas lectoras en la escuela de su vínculo social con el presente, con el pasado y con el devenir mismo de la sociedad.

Dentro de las claves iniciales para comprender el cuerpo simbólico de la memoria, destacamos los hechos que quedan condensados en los recursos literarios, como la metáfora, la intertextualidad o las alegorías presentes en las novelas que remiten al conflicto social y político en Colombia. Lo anterior, sumado a las intersecciones que encuentra Astrid Errll (2005) entre literatura y memoria, por lo menos en tres sentidos: a) en ambas se dan diversos procesos 
de condensación, los cuales crean y transmiten representaciones sobre el pasado; b) ambas se valen de la narración como formato ubicuo de creación de sentido, y c) ambas utilizan modelos de estilo literario como formas convencionales de codificar el devenir de los acontecimientos (p. 198).

Ahora bien, si toda literatura se nos ofrece en forma de lectura, como afirma Alfonso Reyes (1962), entonces las prácticas de lectura literaria pueden llegar a constituir un dispositivo estético de formación en la memoria dentro del contexto educativo; pero aquello implica crear las condiciones de posibilidad para poner el acento de la lectura en la formación humana y 'en la capacidad para 'aprender' de la historia a través de los relatos y narraciones de aquellos que fueron sus víctimas" (Bárcena y Mèlich, 2000).

Con tales premisas, la primera etapa del proyecto en mención consistió en la indagación bibliográfica, desde una perspectiva genealógica que considerara la procedencia y la emergencia del lenguaje literario. Como anota Foucault (1970), hay discursos que tienen una procedencia en determinadas épocas, pero que luego emergen en otras con un efecto diferente al de su origen. Para este caso, se trató de establecer en el ámbito mismo de la memoria novelas escritas a partir del siglo XXI, pero cuyas investigaciones y formas narrativas estuvieran referidas tanto a hechos recientes, como a los ocurridos a mediados o a finales del siglo pasado. El punto de partida de la investigación fue entonces hacer una revisión de este material y de otros títulos que contribuyeran a su comprensión. El que fueran textos que pudieran integrarse a los planes de estudio de los maestros, pero que ante todo, y según el criterio del grupo de investigación, lograran ser sugestivas para los estudiantes, por sus tratamientos dramáticos, personajes o temáticas, constituyeron razones adicionales para esta selección.

Las obras señaladas son: Abraham entre bandidos (González, 2010) sobre la violencia rural de los años 50); Vivir sin los otros: los desaparecidos del Palacio de Justica (Santos, 2010), relativa a la toma del Palacio de Justicia en Bogotá; Los ejércitos (Rosero, 2007), en la que se narra la modalidad de una masacre en
Colombia; El olvido que seremos (Abad, 2006), que se enfoca en el trágico final de un defensor de derechos humanos; El gato y la madeja perdida (Montaña, 2014), cuyo trasfondo lo constituye el exterminio de un movimiento político.

En la segunda etapa del proyecto se trabajó con un grupo de maestros del Instituto Pedagógico Nacional, la que dio pie a la lectura de las novelas seleccionadas ${ }^{2}$ con estudiantes de los grados noveno, décimo y once, en la perspectiva de conversar sobre las obras y consolidar unas propuestas de creación y recreación narrativa a partir de estas. ${ }^{3}$ En ese horizonte, el problema investigativo se enfocó en la pregunta sobre las posibilidades pedagógicas que tiene la lectura literaria de las novelas con visos realistas y testimoniales, para la reconstrucción colectiva de la memoria histórica frente a las últimas seis décadas de violencia política colombiana.

Es de anotar, en este contexto, que en el marco de los actuales procesos de paz, la memoria se constituye en uno de los aspectos más importantes para la educación, por cuanto se perfila en ella la posibilidad de visibilizar ante la ciudadanía el sufrimiento de las víctimas, reconocer los efectos subjetivos de la guerra en una parte de la sociedad colombiana y advertir una forma de comprender lo que se ha denominado experiencias de reparación y de no repetición.

Al respecto, es importante reconocer que la construcción de la memoria en el país ha estado delimitada por la denuncia de las organizaciones

2 La actividad de lectura tuvo lugar de diversas maneras en el Instituto Pedagógico Nacional. Los maestros que acogieron la propuesta desplegaron diversas estrategias de lectura en el aula, en silencio, en voz alta, de manera conjunta, en casa, etc. También hubo estudiantes que una vez socializado el proyecto, realizaron por su propia cuenta las lecturas de estas novelas, sin que mediara un requerimiento particular en una asignatura. Se ha de señalar que el acceso gratuito a diversos ejemplares de los libros constituyó un factor determinante para que la práctica lectora pudiera llevarse a cabo.

3 Estas propuestas de creación se dieron mediante un conjunto de talleres realizados con estudiantes del IPN enfocados a recrear las novelas con múltiples lenguajes artísticos, insinuando otras formas de expresión y comunicación en las que se conjugaron las artes plásticas (dibujo, cómic, pintura, collage, cartografías, instalación) y las artes visuales, apoyadas en el video y los medios electrónicos (fotografía y filminutos). Estas actividades constituyeron la tercera etapa del proyecto que culminó en un Festival artístico de la Memoria. 
de derechos humanos y los discursos oficiales o académicos de corte democrático, lo que ha permitido la difusión en los ámbitos, nacional e internacional, aspectos sobre la violación de los derechos civiles y políticos de los ciudadanos. De igual manera, la presencia de organismos internacionales e instituciones como el Centro Nacional de Memoria Histórica, vienen adelantando una importante labor en los procesos de reparación simbólica de las poblaciones afectadas por la guerra. Así, galerías artísticas, monumentos, campañas, movilizaciones y concentraciones públicas, han acompañado dichos esfuerzos y vienen resaltado el papel del arte en la construcción de la memoria y la paz.

Si bien dichas manifestaciones son de gran envergadura y han estado rodeadas de movimientos de víctimas, organizaciones juveniles, políticas, gremiales, étnicas y de género, dos fenómenos inquietan el desarrollo del presente proyecto: en primer lugar, la emergencia de múltiples discursos sobre el conflicto colombiano sin un eco en la educación ni en los jóvenes; en segundo lugar, su distancia con las prácticas formativas de la escuela.

Con respecto al primero, se destaca el posicionamiento de la epistemología jurídica, la cual tiende a imponer un tipo de verdad, en el entendido de Wittgenstein, cuando advierte que en el mundo la pregunta filosófica es por lo que viene al caso, es decir, por los estados de las cosas, por su comprensión. Lo grave, según él, es que se ha confundido la realidad con lo proposicional. Y esta confusión hizo del pensamiento algo proposicional (Wittgenstein, 1994, p. 45). De esa manera, la historia del conflicto ha estado dominada por un tipo de proposición jurídica que indica el sentido de la verdad y la justicia; lo que ha supuesto una permeabilidad de los postulados éticos, a través de las declaraciones y pactos internacionales y de las estructuras lingüísticas y procedimentales de la normatividad jurídica nacional. En consecuencia, el lenguaje en el nivel de la memoria tiende a legitimarse desde formatos como informes técnicos o estadísticos, demandas y tratados, muy importantes para la investigación y la denuncia, pero insuficientes para el reconocimiento de los dramas humanos de la sociedad y para aquello que le compete a la educación.
En segundo lugar, los procesos formativos de la escuela están al margen de tales juegos del lenguaje y su correspondiente actividad política. Por el contrario, aparecen anclados a ciertos enunciados sobre ciudadanía y convivencia, en los cuales las ciencias humanas mantienen un perfil más de corte retórico. Como dijera Edgar Garavito (1999): "Las llamadas ciencias humanas no pueden ser separadas de un humanismo político que se planteó a la vez como modelo de dominación e instancia de redención" ( $p$. 130). En tal caso, la enseñanza ha tenido el afán de idealizar la verdad desde ciertas premisas morales y no desde otros campos de apreciación, como por ejemplo el arte, que lleva a comprensiones distintas de lo que nos ha venido ocurriendo a lo largo de la historia reciente en el país.

El diseño de esta propuesta investigativa y formativa en la esfera de la memoria se enfrenta a estos dos modos de pensar que priman en nuestra época, y es por eso que se asume que la literatura, en general, y la novela, en particular, abren el campo de percepción de los acontecimientos, optando por reconstruir la dimensión vital de historias singulares que representan el modo de habitar en un país afectado de manera diversa por el conflicto.

Aquí es de especial importancia el lugar del lector, llámese docente, estudiante o investigador, no solo como el receptor de una información, sino como el creador de un campo simbólico de la memoria activado mediante la imaginación narrativa. A este respecto, es necesario advertir la intrínseca relación entre el lenguaje literario y la vida, contrario a la posición de verdad que imponen aquellos discursos que reafirman solo una ideal de justicia. Según Garavito (1999):

Hay poderes económicos que apuntan a la destrucción de la población civil. Hay el tercero incluido, la víctima. Pero hay la posición de fuga, de salida, la posición activa. Esa posición activa corresponde a la posición del tercero excluido. Es decir, la posición de aquel que sin sentirse víctima escapa de los polos en conflicto por medio de mecanismos secretos. (p. 272). 
En efecto, los mecanismos secretos de los que habla Garavito pueden estar en la imaginación literaria, en el universo estético que permite reconocer a lo largo de la historia aquella dimensión humana de dramas y personajes que llevan a leer creativamente, reinventar el presente y afirmar la vida desde un lector que se ubica como un tercero excluido en la educación. De acuerdo con ello, el lenguaje literario establece unos lazos de vecindad con la acción social y con la acción política, y más concretamente, actúa y moviliza cierto tipo de acciones humanas. En el lenguaje literario no se agota la discusión y la proyección política, lo que sí se puede anotar es que este se presenta como una mediación posible en las prácticas educativas de la memoria y la defensa de los derechos humanos.

Tales premisas, como se verá más adelante, llevan a la pregunta por el modo como la literatura contribuye a la construcción colectiva de la memoria en la escuela, provocando un impacto en el ambiente educativo y un reconocimiento de los efectos que ha tenido el conflicto armado en la sociedad.

\section{Memoria, literatura y acontecimiento: un enfoque pedagógico}

La filósofa Martha Nussbaum (1997) ha insistido en que, antes que la razón, están los sentimientos morales, y que estos aparecen tal como son en textos como la novela. Según Nussbaum, la literatura conduce directamente a las condiciones de existencia, por dramáticas que estas sean, y amplía el horizonte del juicio. Y el juicio, unido con la imaginación literaria, crea nuevas relaciones de vínculo social. De ahí que muchos de los autores contemporáneos dedicados a la ética se fijen cada vez más en los textos literarios, al ver en ellos toda una posibilidad de comprender los dilemas de los individuos, sus deseos y contradicciones, más allá del juicio positivo y la normatividad jurídica.

Esta perspectiva tiene mucho que ver con lo que plantea Gilles Deleuze: "captar lo que sucede como injusto y no merecido (siempre es por culpa de alguien), he ahí lo que convierte nuestras llagas en repugnantes, el resentimiento en persona, el resentimiento contra el acontecimiento" (Deleuze, 1996, p. 156). Cuando se reivindica la conciencia sobre los hechos, aparece el anhelo de hacerle explicar a esta lo que realmente ignora, como causa primera que se abroga el poder sobre el cuerpo, intentando, a partir del juicio, colocarse de manera previa a cualquier acontecimiento. Desde la conciencia, el acto y, en consecuencia, el sujeto están siempre remitidos a juicios de lo bueno o lo malo. No podríamos comprender nada de los personajes que crea la literatura desde la perspectiva de un tribunal o de un sistema del juicio. Por el contrario, descubriremos la naturaleza de su relación en el ámbito de lo corporal, si penetramos en el transcurrir de los modos de existencia: en los efectos de pasiones y de acciones que componen los acontecimientos del ámbito narrativo.

Deleuze, por ejemplo, muestra el recorrido de las profundidades en la obra literaria de Lewis Carroll (Alicia en el País de las Maravillas) de la siguiente manera:

Todo empieza en Lewis Carroll con un combate horrible. Se trata del combate de las profundidades: hay cosas que estallan o nos hacen estallar, cajas que son demasiado pequeñas para su contenido, alimentos tóxicos o venenosos, tripas que se alargan, monstruos que nos engullen. Un hermano mayor utiliza a su hermano pequeño como cebo. Los cuerpos se mezclan, todo se mezcla en una especie de canibalismo que junta el alimento y el excremento. Hasta las palabras se comen. Es el ámbito de la acción y de la pasión de los cuerpos: cosas y palabras se dispersan en todos los sentidos o por el contrario se sueldan en bloques indescomponibles. (Delueze, 1989, p. 37).

Por ello, el acontecimiento al ir emergiendo desde la propia profundidad en la expresión literaria, es decir, desde la propia mezcla corporal de personajes, acciones y pasiones, está permanentemente afectado de múltiples maneras. Del mismo modo, el acontecimiento retoma el pasado, pero surge en el presente, tanto que termina desbordando el propio juicio, el a priori, pues va desencadenando progresivamente los efectos de las pasiones y las acciones. El problema de la moral en Deleuze ya no es al nivel de juicio, sino de la percepción. La 
magia de la literatura radica en lograr la conexión de lo imperceptible -aquello que a simple vista no se puede reconocer-con lo perceptible - una forma que nos permite descubrir los enigmas humanos-, trazando de esta manera el plano estético sobre el que reposa el plano literario. Desde cierta lógica racional solo se verán en los acontecimientos posiciones de sujeto y objeto, simulando que mediante un juicio racional el primero domina y representa al segundo, lo que definitivamente evita cualquier contacto con el campo perceptivo correspondiente a los efectos de pasión y de acción.

Por tal motivo, y contrario a otros discursos que han dominado el abordaje del conflicto armado en Colombia, entre estos el jurídico, consideramos que la narrativa literaria se presenta como el cuerpo mismo de la memoria, de acuerdo con el interés y el asombro de un autor y de un lector. El asombro supone explorar lo que hay más allá de lo que aparentemente se conoce. $\mathrm{El}$ asombro frente a experiencias propias y ajenas supone la posibilidad de un nuevo vínculo social, no solo con quienes han sido afectados directamente por un hecho violento, sino con todos los miembros de la sociedad, pues es claro que sensaciones como desconfianza, miedo o inseguridad, entre otras, son fruto de actos de terror con los que se han vulnerado los escenarios de convivencia en determinados contextos locales y regionales de nuestro país.

Particularmente, el paradigma de víctima y victimario que se impone en la historia de nuestra violencia, genera en el imaginario colectivo un tipo de prejuicio o estigma, por parte de la sociedad, ante las poblaciones que han sido objeto de violaciones a los derechos humanos y una cierta permisibilidad ante los hechos que han generado daños emocionales. El estigma se constituye en una mirada externa que mantiene los sentimientos de culpa y somete a las personas afectadas a la condición de objeto de un modelo ajeno a su cosmovisión. Este lamentable panorama pone a las víctimas en una situación de absoluta pasividad y vulnerabilidad, alejadas de sus valores y de su lenguaje. Un trabajo de educación en la memoria mediado por la lectura literaria, se ubica en un lugar totalmente distinto, facilitando el escenario activo de los sujetos, tanto a aquellos alcanzados por un trágico acontecimiento, como aquellos que no han sido directamente vinculados al conflicto armado, pero que viven en medio de él.

Así también, la literatura permite un proceso significativo, pues frente a eventos de gran impacto se tiende a silenciar las emociones y a guardar internamente los efectos de los daños causados. El hecho de encontrar en el lenguaje literario un material que le dé forma a ciertos contenidos de existencia, supone que las sensaciones más íntimas se proyecten socialmente y conquisten un escenario exterior. De esta manera, la literatura emerge como posibilidad de convertir la memoria no en un saber de orden estático y cognitivo, sino en un acontecimiento que puede ser explorado desde las condiciones del presente.

En tal caso, el acontecimiento no conquista un discurso acabado, no cuenta con una explicación última; el acontecimiento hace que el sentido no esté por reconstruirse o por recuperarse, como si se hubiera perdido y se pudiera volver a él. El acontecimiento hace que el sentido esté siempre por producirse, por crearse, por fundarse en cada situación. En este horizonte, una pedagogía de la memoria mediada por la lectura literaria es una pedagogía del acontecimiento y una práctica sensible que nos sumerge en lo inesperado. Pero dicha práctica, por supuesto, requiere del concurso de docentes que inviten e inciten a sus estudiantes a transitar de la mano de un personaje con todas sus peripecias y llegar con él hasta el final, por difícil y doloroso que este tránsito sea, pues esa es la carga biográfica y subjetiva que nos ha dejado el propio acontecer de la guerra en Colombia.

\section{Lectura literaria y reconstrucción de la memoria: trazos de una experiencia}

Nuestra hipótesis de trabajo pedagógico, como ya lo hemos advertido, comporta la idea de que la lectura literaria provee a niños y jóvenes lectores una experiencia estética vinculada con la memoria del sufrir y del padecer, pero también del resistir y sobrevivir, propias de la condición humana. En la 
experiencia concreta desarrollada en el Instituto Pedagógico Nacional, intentamos que las novelas seleccionadas comprendieran parte de esas vivencias que muchos conciudadanos tienen del conflicto armado colombiano. En esa medida, esta lectura nos aproximaría a una memoria simbólica del conflicto y ofrecería posibilidades de comprensión y de reflexión, mediadas estéticamente.

De fondo, subyace la idea de que la literatura puede operar también aquí como una provocación hacia el conocimiento del pasado reciente de nuestro país y hacia la necesidad de situarse frente a esta realidad en la esfera de la discusión pública. Sin embargo, no aludimos al lenguaje literario como una estrategia para llegar al dominio del conocimiento histórico, por demás necesario en las escuelas, sino en destacar el carácter de la lectura literaria como práctica estética que permite atender las experiencias ajenas o que no hemos vivido, para derivar de allí lecciones de una memoria ejemplarizante, tal y como la define Todorov (2008); lo cual significa que sin negar la singularidad de los hechos violentos escenificados en las novelas, veamos en esa forma de rememoración literaria la posibilidad de comparar o apelar a la analogía para construir así un exemplun del cual se extrae una lección o "un modelo para comprender situaciones nuevas con agentes diferentes" (Todorov, 2008, p. 52).

Volviendo a Nussbaum, en efecto, la obra literaria puede ubicar a la sociedad en dirección de esa lectura que interroga por lo que ocurre en un determinado momento de la historia y lo logra, por cuanto vincula la razón a la imaginación, y estas a su vez a la convivencia de lo público. Los tres referentes que entran en juego en dicha práctica de lectura literaria son: el lector, el autor y el mismo texto, que en este caso es el contexto del conflicto vuelto forma estética. La novela inmediatamente entabla un vínculo comunicativo con los acontecimientos; estos tres referentes se encuentran con un amplio espectro de vivencias que necesariamente se afectan. Aquí el problema no se queda en el mensaje de los textos producidos, ni en la interpretación de sus signos o de sus contenidos.
La imaginación literaria no se queda con una reconstrucción lineal de la historia, sino que se extiende a una interpelación sobre las formas de vida y en esa relación dinámica entre lector, escritor y personajes, conduce a circunstancias pedagógicas de interpretación; pero lo hace porque activa emociones, pasiones y sentimientos morales. Es este tipo de sensibilidad la que encontramos precisamente en el marco de las tertulias que sostuvimos con estudiantes de noveno, décimo y undécimo grado del Instituto Pedagógico Nacional, una vez puestas a circular las novelas referidas y leídas en diversos momentos y lugares, con desiguales ritmos y estrategias, pero todas posibilitadas por el escenario de la institución educativa.

Así, por ejemplo, en una de las conversaciones con los jóvenes, liberada del peso de un examen o de la presentación de un informe acerca de lo leído, y más bien recreando un espacio en el que se pudiera compartir y expresar los pensamientos y sentimientos que iban suscitando la trama de una de las novelas, Sara, estudiante de noveno grado, refiriéndose a la lectura de Vivir sin los otros, sostiene lo siguiente:

\section{Yo supongo que a todos nos trajo como un revuelto de emociones al leerla y es una realidad que nosotros veíamos en un televisor y que veíamos muy ajena a nosotros y leer eso, en serio, es como ponerse en los zapatos ya sea de Betty, de Ramiro, de la periodista, pues, del personaje que haya sido y entender, o sea, no entender, sentir más que todo, cual es la realidad que vive el mismo país donde nosotros nacimos.}

Esa otra forma de entendimiento, o, como se precisa allí, de sentimiento, es posible por aquella característica del arte literario que, como nos lo recuerda Jerome Bruner (1999), permite subjuntivizar la realidad, esto es, hacer de cuenta como si. De esta manera, la novela nos aproxima de modos menos triviales a lo que somos y hemos sido como nación. Y, precisamente, en ese marco, leer literatura "otorga extrañeza, hace que lo evidente lo sea menos, que lo incognoscible lo sea menos también, que las cuestiones de valor estén más expuestas a la razón y a la intuición" (p. 160). Pero se trata aquí de otros modos de razonar y otro tipo de saber que no se atiene a las 
estadísticas, al fenómeno noticioso, a las verdades oficiales, o a la supuesta contundencia de los hechos:

Empezamos a leer listo, "Toma del palacio de justicia", tantos muertos, tantos desaparecidos y de esa manera lo registrábamos en nuestro proyecto, pero lo que logran estos libros y lo que logra la literatura es volver a despertar esa sensibilidad humana porque es presentar los datos de una manera completamente distinta, donde usted no está leyendo el informe de que fue lo que sucedió paso a paso, sino que usted está sintiendo cómo sienten las personas y yo creo que eso es lo que logra la literatura. (Valentina, estudiante de grado undécimo)

Creo que esto -se refiere a la lectura de la noveladebe hacernos tener conciencia de nuestra memoria, nos ayudara más adelante a construirnos, no simplemente dejarnos meter los dedos a la boca de "no, mira esto fue lo que paso, la ley hace esto" y ya, sino a progresar e ir más allá. (Luisa, estudiante de grado undécimo)

Ese ir más allá o ese lugar distinto lo posibilita, entre otros, esta frontera indómita, como denomina Graciela Montes (2001) a ese espacio de la imaginación que se erige a través de la lectura, en medio de la vida cotidiana y prosaica, para mostrarnos que hay algo de profundo e incierto en todo arte poético y literario. Se trata de una zona de intercambio entre el adentro y el afuera, entre el sí mismo y lo otro: el mundo del lector y el mundo de la cultura y por tanto el del nos-otros. La frontera, sostiene la autora, es transición entre un ser y un hacer libre que contiene sus propias reglas de juego, su propio espacio y su propio tiempo (cfr. Montes, 2001, pp. 52-53).

Por ello, la lectura literaria, "como la cultura, como toda marca humana, está instalada en esa frontera" (p. 52) y por eso es tan difícil de asirla, de curricularizarla, de volverla deber escolar, de imponerla como tarea o convertirla en imperativo. En esa perspectiva, y en el marco de esta experiencia formativa de la que aquí intentamos dar cuenta,

4 La toma del Palacio de Justica por parte del movimiento guerrillero M-19 y la retoma agenciada por el Ejército Nacional, ocurre el 6 y 7 de noviembre en 1985, y deja como consecuencia cerca de cien personas muertas y un saldo de once trabajadores de la cafetería desaparecidos. es posible que la lectura deje de ser una tarea por algunos momentos, para convertirse en ese hilo narrativo que nos conduce de vuelta a nuestra propia vulnerabilidad humana:

Yo lloré con el final porque es que "uish", yo iba en el bus, es que ese final... es el pedazo más descriptivo que tiene todo el libro, supongo que debe ser para que uno sienta lo que él está sintiendo en ese momento. (Sergio, estudiante de grado undécimo)

Uno de esos apartes (pedazos), al que hace referencia el estudiante, se encuentra en las últimas páginas de Vivir sin los otros:

Su cuerpo se estaba desgonzando definitivamente y Ramiro percibió, sin comprender aún, que solo pocos segundos le separaban de la muerte. Su inconsciencia emprendió fuga hacia el rumor de la eternidad. Ramiro todo se fue con ella, lenta y sigilosamente. Sacó la foto de sus cuatro hijas del bolsillo de su camisa. Primero besó a cada una en la mejilla, luego abrazó a las cuatro juntas. Le dedicó a Bety este acto de amor, como si fuera el son cubano que bailaron el día de sus quince años. Y con el último suspiro se entregó para siempre al orgullo de padre y de amante que acababa de arrebatar a sus torturadores. (González, 2010, p.163).

Como se observa, cuando se crea en el ambiente escolar condiciones de posibilidad para erigir este territorio de frontera que nos mantiene entre ese ir y venir, quizá algo (les) sucede, algo (les) acontece y, por tanto, algo puede transformarse en los jóvenes estudiantes:

A través de este libro también me di cuenta que uno puede ganar más herramientas para comenzar a transmitir ese sentimiento y si no es del todo recuperar, reconstruir esa sensibilidad que hemos estado perdiendo porque a fin de cuentas todos somos humanos independientemente de las ideologías, pensamientos, religiones, todos tenemos un ser humano adentro y eso es lo que nos hace a todos en común. (Daniel, estudiante de noveno grado).

En este escenario de diálogo acerca de la lectura de estos libros que abordan dramas humanos de la guerra, los estudiantes no solo dan cuenta de un contenido o de una forma, de una técnica narrativa o de un punto de vista del escritor, sino que, sin 
desconocer estos y otros detalles de composición, se preguntan por su propia manera de habitar el país, por el sentido de lo público y por su papel como jóvenes. Muchas de sus expresiones al respecto, son contundentes:

Hay que ser propositivos, y aqui hay que traer unas propuestas claras y no decir que entonces que la juventud no..., porque yo he oído muchos comentarios de ese estilo, a muchos, digamos adultos, que la juventud "no sirve", que la juventud es basura, perdón la expresión pero ellos lo dicen así, y a mí me enoja porque la juventud es la esperanza, o sea los niños son la esperanza, somos la esperanza de un mejor país, somos la esperanza de que todo esto, digamos las desapariciones, las víctimas sean recordadas, somos la esperanza de tener memoria histórica. Entonces, creo que la clave aquí mirando la problemática es como tal la juventud, la juventud es la esperanza, tenemos que meterle la ficha como se diría, para poder hacer la transformación. Yo veo que en mi vida ese es el eje, ese el objetivo para hacer un cambio. (Cindy, estudiante de noveno grado).

Estas palabras, consideramos, son más que opiniones, y constituyen formas de percepción y de sensibilización provocadas por este tipo de lectura literaria encauzada siempre por aquello que le ocurre a un personaje en un lapso de tiempo concreto y un lugar. Junto a Vivir sin los otros, otra novela que despertó una posición activa de los estudiantes ante la memoria del conflicto fue también Los ejércitos (2007), de Evelio Rosero, en la que leemos:

-Te repito que me duele que cualquier hombre sea retenido en contra de su voluntad, tenga lo que tenga, o no tenga lo que no tenga, porque también se están llevando a los que no tienen, mejor dicho, esto está de desaparecer primero uno, voluntariamente, para que no nos desaparezcan a la fuerza, que debe ser mucho peor. Agradezco mi edad a medio paso de la tumba, y compadezco a los niños, que les aguarda un duro trecho por recorrer, con toda esta muerte que les heredan, y sin que tengan la culpa. (p. 59).

Precisamente, la importancia de la imaginación narrativa frente a la vida pública radica en posibilitar esta interacción entre aquellas aspiraciones de la humanidad y las circunstancias particulares de los sujetos en un escenario abierto de signos de la cultura. La novela ya no expresa el hecho, sino que busca darle sentido. Es más, la expresión literaria deja entrever que aquellas preocupaciones humanas generales no son de naturaleza distinta a las de los sujetos que leen los dramas de la humanidad, lo que se logra gracias a la ficción. Así se presenta la simpatía del lector con los personajes y el autor, pues sin perder su propio escenario vital, puede sensibilizarse ante lo que otros viven, en el marco de una pluralidad de interpretaciones. En definitiva, lo que anota Nussbaum sobre la novela ayuda a pensar la experiencia de lectura literaria en el ámbito educativo y cultural desde la perspectiva de la memoria:

La novela, reconociéndolo, apela en general a un lector implícito que comparte con los personajes ciertas esperanzas, temores y preocupaciones generales, y que por ese motivo puede formar lazos de identificación y simpatía con ellos, pero que también vive en un ámbito distinto y necesita informarse sobre la situación concreta de los personajes. (Nussbaum, 1997, p. 28).

\section{Experiencia estética, novela y formación ética: enclaves de la memoria histórica}

La vivencia de esta experiencia estética de la imaginación, únicamente posible o realizable aquí mediante el acto de lectura, se toca indefectiblemente con la dimensión ética, justamente porque el arte no es una mera cosa, no es algo, sino sobre algo, así que como signo, representa un modo de ver el mundo, en cuanto tal. Los objetos estéticos, como nos lo recuerda Daniel Innerarity (2002) "muestran algo en virtud de que lo muestran; hacen elocuente la experiencia a partir de la cual hablan, en la medida en que configuran expresivamente la experiencia en cuestión" (p. 23).

Ahora bien, son unos rasgos específicos o una configuración expresiva propia de la novela lo que nos permite argumentar a favor de una relación singular entre la literatura, la lectura como experiencia estética y la interpelación ética en un lector. En ese sentido, apelamos a los planteamientos de 
Joan-Carles Mèlich (2010) quien sostiene que la novela despliega un espíritu o un pensamiento

[...] que nos reta a un aprendizaje, a un recorrido netamente formativo, a un camino en que ya no hay, ni puede haber 'ideas claras y distintas', en el que no existen puntos de apoyo trascendentes al espacio y al tiempo, en el que no hay una finalidad o un sentido último que podamos alcanzar. (p. 73).

Se trata, en esta perspectiva, de una ética narrativa o literaria, en cuanto ética de la compasión, propia del espíritu de la novela, por cuanto el elemento biográfico de toda vida se realiza plenamente en ella y junto a este, la condición corpórea, esto es, que siempre se trata de un cuerpo que vive, siente, sufre, conoce. De ahí el carácter singular y situado de esa existencia. Así, sostiene Mèlich, lo que sucede en el lenguaje literario no les sucede a individuos sino a seres singulares, únicos e irrepetibles, de carne y hueso, que nacen, sufren y mueren, tal como nosotros. Y les sucede, además, en un lugar (dónde), en un tiempo (cuándo) y de un modo (cómo) (cfr. Mèlich, 2010, pp. 80-83).

De acuerdo con este autor, la singularidad, la situación, y la biografía son rasgos inspirados en el espíritu de la novela, que junto a la ambigüedad, la ausencia y la asimetría permiten situarse en una ética de la esfera íntima y en una ética de la situación como forma básica de la existencia humana, a contrapeso de una ética universal o metafísica. Si el factor biográfico es la base literaria de esta ética, la ambivalencia pervive y subsiste en el texto literario como en la vida: no hay manera de anticiparse, de ser competente allí, puesto que "tanto los personajes y las situaciones como nuestras lecturas e interpretaciones siempre son susceptibles de ser 'de otro modo', de ser revisadas, de ser reinterpretadas" (p. 83).

En cuanto a la ausencia, como rasgo de la novela, llegamos a ella por la misma vía ineludible que por la memoria. Los textos literarios nos muestran que hay algo aún que no ha sido clausurado, que en el presente habitan deudas pendientes. Alguien nos ha dejado una herencia, sostiene Mèlich, y nos corresponde decidir qué hacer con ella. Finalmente, está la asimetría entre diversos polos: el lector y lo escrito, lo propio y lo extraño, el sí mismo y el otro. No hay diálogo aquí, sostiene, sino interpelación y respuesta íntima. La ética narrativa o inspirada en la literatura no es la del consenso, la reciprocidad, la simetría, la comunicación o las competencias, definitivamente (cfr. Mèlich, 2010, pp. 86-87).

La mediación del arte literario para pensar los asuntos humanos no es entonces un problema de indiferenciación entre la dimensión ética y la dimensión estética o la inadecuada escisión del arte de su esfera propia de saber. No abogamos aquí por la unidad y la coherencia entre estos ámbitos diferenciados, pues reconocemos que la emancipación moderna del arte consistió justamente en lograr un horizonte propio para la estética, diferenciado de los horizontes de la lógica, la ética y la política.

Lo que intentamos sostener hasta aquí es que, en efecto, como señala Innerarity (2002), hay una función social y genuina del arte que consiste en "articular formas de percepción del mundo y representar imaginativamente posibles reacciones frente a ese mundo" (p. 27). Paradójicamente, para poder percibir tales representaciones o para que ellas tengan lugar en la imaginación, requerimos muchas veces un distanciamiento frente a ese mundo. Dicha distancia es el lugar que aquí le otorgamos a la mediación del lenguaje literario, y la que permitirá, quizás, que podamos ampliar la estrechez de nuestra propia mirada y de la sociedad en la que vivimos.

Podemos decir, por último, que si los discursos y las prácticas formativas producen efectos en el modo en que se constituye el carácter o el alma de una nación determinada y de los ciudadanos que la conforman ( $c f r$. Guevara, 2015), estamos ante un escenario fundamental para proyectar otros discursos y otras prácticas educativas, que le den paso a este lenguaje literario y a estos otros modos de leer en la escuela. Ello implica que la lectura literaria no siempre esté sujeta a la rentabilidad escolar, sino a una disposición sutil y cálida para acompañar a los estudiantes por ese trayecto y estar prestos para acoger su palabra, dialogar con ellos y permitirles preguntar sin temores, expresar lo que piensan ante los otros y abrirse y abrirnos como docentes a la 
posibilidad de repensar nuestras propias certezas, opiniones e interpretaciones, a la luz de aquello que el otro tiene por decir y por contar.

En este enclave, la memoria histórica tiene mayor sentido si los jóvenes y los niños la reconstruyen $\mathrm{y}$ al hacerlo se descubren como fundadores de un pueblo y de un país que necesita hoy más que nunca de sus ideas creadoras. A lo largo de estos años hemos heredado conflictos, pero también versiones, silencios, umbrales de la verdad y la mentira. Así que consideramos que solo una paciente actitud de escucha y comprensión como la que nos exige la lectura literaria de una novela, puede ayudarnos a encontrar la voz que el pasado reciente no ha podido hallar, por miedo, por desconocimiento o por vergüenza. Quizás una profunda lectura de estos dramas humanos que han marcado la experiencia de las generaciones que se van y las que llegan en medio de un largo conflicto armado, pueda permitirnos desentrañar algunas señales del presente. $Y$ en esa medida, sigamos encontrándonos con jóvenes que hoy, después de leer una novela colombiana como las que aquí aludimos, puedan seguir interrogándose en clave de memoria del pasado, pero también con horizonte de futuro, un asunto tan decisivo para el país como el siguiente:

Bueno, quizás nosotros no seamos la generación de la paz, pero sí podemos ser la generación que sea capaz de no seguir pasando la pelota y decir esta generación no fue, la siguiente, entonces tal vez seamos esa generación que se empiece a formar $y$ que se fusione con las próximas generaciones de la paz. (Valentina, estudiante de undécimo grado).

\section{Referencias}

Abad, F. H. (2006). El olvido que seremos. Bogotá: Planeta.

Bárcena, F. y Mélich, J. (2000). La educación como acontecimiento ético. Natalidad, narración y hospitalidad. Buenos Aires: Paidós.

Bruner, J. (1999). Realidad mental y mundos posibles. Los actos de la imaginación que dan sentido a la experiencia. Barcelona: Gedisa.

Centro Nacional de Memoria Histórica (CNMH) (2013). ¡Basta Ya! Colombia: Memorias de guerra y dignidad. Bogotá: Imprenta Nacional.
Cortázar, J. (2013). Clases de literatura. Colombia: Alfaguara.

Deleuze, G. (1989). Lógica de sentido. Barcelona: Paidós. Deleuze, G. (1996). Crítica y clínica. Barcelona: Anagrama. Errl, A. (2012). Memoria colectiva y cultura del recuerdo. Bogotá: Ediciones Uniandes.

Foucault, M. (1970). La arqueología del saber. Madrid: Siglo XXI Editores.

Fuentes, C. (2011). La gran novela latinoamericana. Ciudad de México: Alfaguara.

Garavito, E. (1999). Escritos escogidos. Medellín: Universidad de Antioquia.

González, S.F. (2010). Vivir sin los otros, los desaparecidos del Palacio de Justicia. Bogotá: Ediciones B.

González, T. (2010). Abraham entre bandidos. Bogotá: Alfaguara.

Guevara, C.A. (2015). Si hablamos de formación a las cosas mismas, se educa para la responsabilidad con la cultura. Conferencia de la Cuarta Lección Ordinaria de la Cátedra Doctoral "La filosofía de la educación como sustrato de la formación" en el marco del Doctorado Interinstitucional en Educación (DIE). Universidad Pedagógica Nacional.

Innerarity, D. (2002). Pequeña apología de la experiencia estética. Barcelona: Paidós.

Mèlich, J.C. (2010). Ética de la compasión. España: Herder. Montaña, F. (2014). El gato y la madeja perdida. Bogotá: Alfaguara.

Montes, G. (2001). La frontera indómita. En torno a la construcción y defensa del espacio poético. México: Fondo de Cultura Económica.

Nussbaum, M. (1997). Justicia poética. La imaginación literaria y la vida pública. España: Andrés Bello.

Reyes, A. (1962). Apolo o de la literatura. En Obras completas. Tomo xiv. México: Fondo de Cultura Económica.

Rosero, E. (2007). Los ejércitos. México D.F.: Tusquets.

Todorov, T. (2008). Los abusos de la memoria. España: Paidós.

Wittgenstein, L. (1994). Tractatus Logico Philosophicus. Barcelona: Altaya. 